\title{
An exploratory study of the role and training needs of one primary care trust's professional executive committee members
}

Maxine Offredy University of Hertfordshire, Faculty of Health and Human Sciences, Hatfield, UK

This paper provides a summary of an exploratory study based on an interpretive approach, aiming to elucidate how professional executive committee members of one primary care trust see their role and the training they need to fulfil their functions. The effective delivery of local and national health priorities in the newly created PCT depends on these members having the knowledge and skills needed to carry out their work. At the time of the study, no one had assessed whether or not the members had the requirements for their role. The study was conducted in $\mathbf{2 0 0 2}$ during the first six months of the creation of the PCT. Using questionnaires and semi-structured interviews, the study examined the perceived training needs of the 26 participants. Data analyses were in two stages. Analyses of the questionnaires involved entering the responses into a statistical programme. These were categorized into four areas: intellectual, financial/commissioning, service issues and other issues. Matrices of the responses were developed for the group and for each executive participant. In addition, a further matrix was designed, with a weighting applied, to show the order of importance for each competency. The second stage of data analysis involved content analysis of the verbatim transcripts. Themes identified from the coded analysis include the participants' views of the direction of the professional executive committee, and concerns about them. The paper shows that the training needs of the committee members are not so easily determined because of lack of clarity of their role, and the part they play in the development of managed clinical networks and in securing co-ordinated and seamless care for the PCT's patient population. The paper concludes by suggesting that some of the difficulties faced by the executive committee members were not of its own making, but were due to the rapid nature of organizational change in the National Health Service. This project contributes to the knowledge base about executive committee members, group interaction and dynamics, as well as having practical implications for delivering both local and national health targets. Future research could address the extent to which the PEC's role has been clarified and whether this has been helpful in contributing to the redesign of services.

Key words: primary care trust; professional executive committee; role clarification; training needs

\section{Introduction}

The UK Government's centrepiece for reforming the National Health Service (NHS) is set out in

Address for correspondence: Maxine Offredy, University of Hertfordshire, Faculty of Health and Human Sciences, College Lane, Hatfield, Hertfordshire, AL10 9AB, UK. Email: M.V.Offredy@herts.ac.uk

(C) 2005 Edward Arnold (Publishers) Ltd
The NHS Plan (Department of Health, 2000). The document provides an outline for a paradigm shift from a centralized, bureaucratically controlled NHS to a devolved patient-centred health care service, underpinned by an increase in spending over the next five years. The redesign of the NHS is reinforced in Shifting the Balance of Power (Department of Health, 2001), which states that organizational changes to support the long-term 
plans include the creation of strategic health authorities (SHA) and primary care trusts (PCTs). This paper provides a summary of an exploratory study based on an interpretive approach, aiming to elucidate how professional executive committee (PEC) members see their role and the training they need to fulfil their functions. The interpretive paradigm is concerned with the social world, in which reality is not fixed but varies with context and is influenced by, for example, culture, gender and politics. Thus, the findings of the research are descriptive rather than predictive or explanatory.

The effective delivery of local and national health priorities in the newly created PCTs depends on the PEC members having the knowledge and skills needed to carry out their work. Their work involves 'lead(ing) the board through detailed thinking on priorities, service policies and investment plans' (NHS Executive, 1999: 13). In other words the PEC will be the 'engine room' (NHS Executive, 1999: 13) of the PCT. However, as yet no one has assessed whether or not they have the ability to meet these requirements. Little is known about how the PEC approach their work, and their likely training needs. This project will contribute to the knowledge base about the PEC, group interaction and dynamics, as well as having practical implications for delivering both local and national health targets. The paper has four major sections beyond this introduction: organizational structures, literature review, the case study and conclusions.

\section{Organizational structures}

SHAs provide a framework for developing health and social care services across the range of local NHS organizations. This means that SHAs are responsible for whole system planning and performance management across organizational boundaries and networks, for a specified number of PCTs, to secure improvements for patients. They will also play a role in conflict management and support improvement strategies developed by NHS trusts and PCTs.

PCTs are the lead NHS organization in assessing need, planning and securing all health services and improving health. PCTs, lying at the heart of the government's reforms, have opportunities to engage local communities in the decision-making processes about health services. PCTs are expected to prepare plans for health improvement, which recognize local diversity. They also work in partnership with local stakeholders such as, voluntary groups, education and housing authorities to deliver wider objectives for social and economic regeneration. PCTs are also charged with taking responsibility for the full range of services for their local populations, including commissioning. They have responsibility for the management, development and integration of all primary care services. ${ }^{1}$ The administrative arrangements for PCTs are complex; Box 1 refers to the PCT under discussion.

Although the Department of Health emphasizes the need to have practising clinicians as the driving force with regard to the implementation of the core objectives of PCTs (identified below) whilst allowing local flexibility in how this is achieved, both the consultation document for the PCT under discussion and the Department of Health's guidance (NHS Executive, 1999; Department of Health, undated, 2002b) are vague about the role and responsibilities of how clinical leadership in the PCT will be developed. All PCTs have three objectives:

- to improve the health of the local community

- to secure the provision of a full range of services and

- to integrate heath and social care (Department of Health, 2002a).

The role and responsibilities of the PEC emanate from these objectives and normally, the type of training that should be provided have typically been based on the determination of training needs within an organization (Taylor and O'Driscoll, 1998). However, the paper will show that the training needs of the PEC are not so easily determined. The following section addresses the second major aspect of the paper, the literature review.

\footnotetext{
${ }^{1}$ The general guidance and governance arrangements for PCTs are set out in Primary Care Trusts: Establishing Better Services (NHS Executive, 1999). There is limited scope for some local flexibility in the design of PCT arrangements. However, they must comply with the key principles of public accountability, public involvement, professional influence and probity.
} 


\section{Box 1}

The study site's PCT board comprises:

- Chair (non-executive)

- Six non-executive directors

- Chief executive

- Director of finance

- PEC chair

- Director of nursing

- Clinical governance lead

- Director of public health

The role of the board is to set the organization's strategic aims, ensuring that the necessary financial and human resources are in place for the organization to meet its objectives, and review management performance.

The PEC has 15 members comprised of:

- Chief executive (also sits on PCT board)

- Director of finance (also sits on PCT board)

- Director of public health (also sits on PCT board)

- Five GPs (including PEC chair who also sits on PCT board)

- Three nurses (including director of nursing who also sits on PCT board)

- Social services representative

- Consultant employed by the PCT

- Allied health professional

- Pharmacist

The role of the PEC reflects a unique position of clinical leadership within the PCT. It is expected that the PEC will provide much of the clinical direction and sound strategic advice for the PCT. Key areas for the PEC include interfacing with acute sector clinicians, ensuring the PCT has a whole-systems approach to care, delivery of the clinical agenda and health improvement.

The management team is comprised of:

- Chief executive (also sits on PCT board)

- Director of finance (also sits on PCT board)
- Director of nursing (also sits on PCT board)

- Director of public health (also sits on PCT board)

- Director of service modernization

- Director of primary care services

- Director of specialist services

- Head of corporate development

This body has the remit and decision-making powers defined by the board to which they are expected to report at agreed intervals. Some key areas of responsibility include development of local commissioning strategies and service agreements, creation of local delivery plans, which describe NHS and joint NHS and social care priorities in the area. The plans are defined by targets and delivery dates set out in the NHS Plan (Department of Health, 2000) and national service frameworks for particular patient groups and conditions.

Corporate governance: In addition to statutory committees (audit, remuneration, clinical governance, risk management and the PEC committees) of the board, this includes the line management arrangements for the PCT employed staff.

Clinical Governance: The remit of clinical governance in the PCT goes beyond those services provided by the PCT employed staff to all services provided by or in the name of the PCT. The director of nursing and a medical member of the PEC, both of whom sit on the PCT board, have a joint lead.

Partnership: The PCT is committed to working in partnership with other agencies and the public to achieve and deliver the best services for its population.

\section{Literature review}

When this review was undertaken, there was no literature on the PEC as an entity. Rather, the literature relates to the contribution different professions (including nurses, doctors and pharmacists) within the group have made to commissioning and management in the post-1980s NHS. The literature review will therefore focus on commissioning and management as they form part of the functions of the PEC.

An electronic literature search was conducted on websites of the Department of Health and NHS and databases of Knowledge Access 24 
Hours (KA24), Medical Literature On-Line (MEDLINE), Cumulative Index to Nursing and Allied Health Literature (CINAHL), King's Fund, Cochrane and Bath Information and Data Services (BIDS), and covered the years 1992 to 2002. The initial search terms used were: 'Professional Executive Committee' and 'Executive Committee'. No information was available regarding the PEC's role. Subsequent search terms used were 'nurse commissioning/management', 'doctor commissioning/management' and 'nurse/doctor/ purchasing'. Approximately 200 articles were revealed by the combined databases, some of which were replicated. The librarian at the Royal Pharmaceutical Society was contacted and a record of 84 articles relating to pharmacists' contribution to primary care groups and trusts (PCG/Ts) was obtained. Only articles with specific reference to professionals' involvement in the commissioning and management of health care were included as this provided issues relevant to the project. Additional articles searched included those recommended by experts in the field and those found by manual search of the libraries of the King's Fund and the Royal College of Nursing. The literature search yielded more items than could be included in this review, and the studies reviewed here were selected on the quality of information they provided. The quality of the studies was determined by an adaptation of the evaluation criteria for research appraisal used by Duffy (1985) and Greenhalgh (1997). It was not the purpose of this literature review to provide a critique of the whole of the literature, but to identify the major themes emerging from the research findings.

The research literature on nurses' contribution to the commissioning and senior management process is sparse. However, there are papers highlighting the contribution nurses can make to the purchasing or commissioning role (Harvey, 1994; Benton, 1997). In the early 1990s, nursing directorates of the NHS commissioned three reports (South East Thames Regional Health Authority (SETRHA), 1992; King's Fund College, 1993; Department of Health, 1994) to investigate the issues around purchasing and the contribution of nurses to that process. All three reports took a qualitative approach to data collection. The SETRHA (1992) study selected 25 senior representatives from both within and outside the NHS on an opportunistic basis according to availability.
This selection process limits the generalizability of the study. The King's Fund College (1993) study utilized a seminar organized along similar lines to a consensus conference to collect data. Whilst this approach offers the opportunity to involve large numbers of people, a drawback is that not all members will participate in the debate. Structured interviews were used in the Department of Health (1994) project where 43 organizations were involved. All three studies highlighted the important contribution nurses make to the commissioning process, but major drawbacks included the ability to think strategically, particularly in relation to 'moving across the boundaries of care' (SETRHA, 1992: 48), the difficulty nurses have in articulating and valuing what it is they bring to health care decision- and policy-making. Recommendations to increase nurses' contribution to strategic discussions and decision-making include education and training in epidemiology, health economics, research methodology, management theory and information technology (King's Fund College, 1993; Department of Health, 1994). The methodology of the Department of Health (1994) study was the most robust of the three reports. However, it should be remembered that in 1992 purchasing was in its early stages of development and that the input needed from a variety of professional groups would become clearer.

Department of Health-funded research looked at the managerial responsibilities of 271 senior executives involved in delivering health care within the NHS. 'Senior executives' included 'doctors, nurses and other health professionals who in addition to, or instead of, their clinical or health responsibilities, had significant managerial responsibilities for the commissioning or delivering of health care' (Dawson et al., 1995: 1). Data collection was multidimensional and included interviews, documents, field notes, and selfadministered questionnaire sheets. The results of the study were presented under six areas, one of which was managerial activity: competence, roles and responsibilities. Key issues arising from this area included essential and desirable competencies set within the organization's strategic objectives and the need to develop the capacity to manage across functions and professions and, particularly within purchasing, across organizations (Dawson et al., 1995). More recently, Kaufman (2002) investigated nursing's contribution to 
commissioning in primary heath care and made similar findings to the above studies. Constraints to nursing contribution to commissioning included conflict among themselves and poor interprofessional collaboration.

A number of studies have addressed the doctor's role in management activities of the NHS from a variety of perspectives (Fitzgerald and Sturt, 1992; Burgoyne and Lorbiecki, 1993; Fitzgerald, 1994; Thorne, 1997). They sought to explain the types of roles adopted by doctors, the main one being clinical director (Fitzgerald and Sturt, 1992). Although not a research study, Fitzgerald and Sturt (1992) sought to show that collaborative working between doctors and managers is essential in health care. Its inclusion in this literature review is relevant as the article suggests a set of tasks for clinician managers and the issues of training, support and development, which are prerequisites to effective management performance. Burgoyne and Lorbiecki's (1993) study extends the debate on how doctors are becoming more involved in management. Their qualitative study interprets the data from in-depth interviews with 60 unit-based clinicians. The study found that the transition into management requires additional skills and changes in orientation, which in turn require forms of learning with which the doctors were unfamiliar. The study identified roles which were deemed needed by clinical mangers, including planning and managing clinical activity in terms of activity and case mix in relation to contracted work (commissioning), understanding and working with organizational complexity and quality/audit issues. Burgoyne and Lorbiecki (1993) identified roles that were more complicated and strategic than those advocated by Fitzgerald and Sturt (1992).

Two longitudinal studies have been undertaken, in 1994 and 2002, looking at doctors' roles in management and decision-making. Fitzgerald (1994) provided an account of the issues of drawing 31 clinicians into management roles and into the management process. The clinicians in this study were unusual in that they all studied management (even if superficially). Findings include the clinicians' desire to influence the form of care provided, and in some cases to improve on the way in which decisions have been taken in the past. A limitation of the study is its small cohort; the clinicians involved in the study were a skewed group because of their interest in management and their wish to influence management decisions. The study suggested that as rapid changes occur, clinicians assume roles which were ill-defined, resulting in ineffective use of their skills.

In 2002, Wilcocks and Conway examined the shift from competition (in the internal market of the NHS) to relationships based on collaboration and partnership of one PCG during its first year of operation. The findings from this qualitative report confirm the results of similar work in identifying key features, such as the importance of prior experience of involvement at board level; the importance of developing working relationships with medical and non-medical members and difficulties in gaining public involvement in the decision-making process.

The literature (although not all research-based) on pharmacists' contribution to the reformed NHS espouses the critical role they can play, particularly in effective management of medicines in all settings (University of Birmingham, 2000; Maddock, 2001; Craig, 2002). The new responsibilities of the PCTs (Department of Health, 2001) may present conflicting dilemmas for some pharmacists who are PEC members with regard to probity when decisions have to be made about commissioning and, separately, surveillance of professional services and resources (Maddock, 2001). Craig's (2002) survey of PEC pharmacists found that they were confident in their ability to understand a range of organizational, professional and community cultures, in addition to being able to present the views of their peers and communicate PCT policies to them. Areas where pharmacists felt there was room for improvement included their management of the interface with independent contractors; the ability to be innovative and to understand the role of public health. Lack of time was a barrier to respondents of the survey working effectively. Some pharmacists reported feeling as 'outsiders' as many other members of the committee had been on PCG boards.

Common threads seen in the literature are a lack of strategic, managerial and financial competence, and tension between the professionals and managers who have different sets of values and assumptions.

The third major section of the paper, the case study, is discussed next. 


\section{The case study}

The study site is a borough situated in the south east of England and has a resident population of approximately 207000 people (Office for National Statistics (ONS) 2001). The borough has an ethnically and socio-economically diverse population. The census data for 2001 estimated that $58.8 \%$ of the borough's population was white and $41.2 \%$ non-white groups (ONS, 2001). This is in contrast to the 2001 national census where the white and non-white proportions were $90.9 \%$ and $9.1 \%$, respectively. Of the borough's non-white groups the highest proportion, approximately $22 \%$, are Indians, compared with a national average of $2.1 \%$ (ONS, 2001). Approximately $14.4 \%$ of the population of the borough are over the age of 65 years. As the projection of the elderly population increases this will have important implications for the planning of health and other services. There are an estimated 6000 to 8000 refugees in the borough, and although there are no statutory barriers to refugees accessing primary care, they often have difficulties due to lack of knowledge about the system and language barriers. There are four areas within the borough that are more deprived than the national average. The level of unemployment is $3.1 \%$ and is slightly lower than the national average of $3.4 \%$. The major causes of death in the borough are circulatory disorders and cancer.

\section{Sample}

The sample consisted of the entire population (15) of the PCT's PEC members (outlined earlier). In addition, six types of stakeholders of the PCT were randomly selected and included in the study. These were:

- a senior member of the local acute trust

- two general practitioners (GPs) (one from each of the two previous PCGs)

- a representative from the voluntary sector

- a patient representative

- a local authority representative

- a focus group comprising five community nurses giving a total of 26 participants.

The purpose of interviewing stakeholders was to glean understanding of how they perceived the role of the PEC, and the skills and knowledge that they would expect of its members to carry out the tasks.

\section{Procedure}

The idea for the project was outlined in a proposal to the PEC and presented to them at one of their monthly meetings. All members were in favour of participating in the study. A full proposal was completed for ethical approval and submitted to the research and development committee of the PCT and subsequently to the local research ethics committee where full approval was granted. The study took place in 2002, during the first year of the PCT. Methods consisted of two questionnaires and an interview.

Two questionnaires (Table 1 and Table 2) were designed based on the competencies and qualities outlined in Primary Care Trusts: establishment, the preparatory period and their functions (Department of Health, undated) and from literature identifying the qualities that would be expected of senior managers. These form part of the data collection strategy. An information letter, together with the questionnaires, were sent to the 15 PEC participants two weeks prior to interview, informing them about the conduct of the study, including the approximate length of the interview. A self-addressed envelope was included in the letter for the return of the questionnaire through the internal post. Each questionnaire was numbered 1 to 15 so that specific training needs could be tailored for individuals. This information would be given to the chair of the PEC and chief executive of the PCT. The PEC members were informed of this and were satisfied with the procedure. However, it was stressed that published data resulting from the research would not be attributable to named individuals.

A different letter was sent to the stakeholders two weeks prior to interview informing them of the purpose of the study. Interview appointments were made with all participants. Thus, two different schedules of semi-structured interviews were devised for the two groups. The taped interviews lasted between 15 to 50 minutes. The purpose of the interviews was to expand on issues not covered by the questionnaires and to explore the views of the participants about the role of the PEC.

\section{Data analysis}

There were two stages to the data analysis: the first involved analyses of the responses from the questionnaire relating to training needs, and the second required verbatim transcribing of the 
Table 1 Knowledge and skills (for each item, please place a tick in the column that corresponds with your answer)

List of skills and knowledge

Degree of possession

\begin{tabular}{|c|c|c|c|}
\hline Possess & $\begin{array}{l}\text { Possess but } \\
\text { would like } \\
\text { further } \\
\text { training }\end{array}$ & $\begin{array}{l}\text { Do not possess } \\
\text { skills and would } \\
\text { like training from } \\
\text { first principle }\end{array}$ & $\begin{array}{l}\text { Not relevant } \\
\text { to me in my } \\
\text { job as a PEC } \\
\text { member }\end{array}$ \\
\hline
\end{tabular}

\author{
Strategic understanding (long-term implications \\ of decisions) \\ Analytical ability \\ Evaluation of organizational performance \\ Financial planning/forward budgeting \\ Controlling financial resources \\ Developing new services \\ Health needs assessment \\ Cultural flexibility (ability to develop in-depth \\ understanding of organizational, professional \\ and community cultures) \\ Integrator (clinical and corporate agenda) \\ Evaluating service delivery \\ Evaluating contract performance \\ Managing service delivery \\ Managing across organizational boundaries \\ Negotiation of service contracts \\ Work and develop plans and strategy with other \\ agencies across NHS, social services, voluntary \\ organizations and other stakeholders \\ Innovativeness \\ Assessment of quality and effectiveness of \\ health care services \\ Risk management \\ Medicines management \\ Marketing your services \\ Team building \\ Time management \\ Computing and IT \\ Interpreting data \\ Goal direction \\ Other, please specify
}

transcripts. Analyses of the questionnaires involved entering the responses into a statistical programme (SPSS). These were later categorized into four areas: intellectual, financial/commissioning, service issues and other issues. Matrices of the responses were developed in all four areas for the group and for each PEC participant. Table 3 shows the matrix for the intellectual training needs area for the group, and Table 4 identifies the perceived training needs for two PEC participants. These tables are illustrations of the kind produced. In addition, a third matrix (Table 5) was designed to show the order of importance for the four categorized areas. This group matrix had a weighting applied to each competency to give the order of importance.
The second stage of data analysis involved a copy of the verbatim transcripts being given to a colleague, who was not involved in the research, for coding. Comparisons of coding from the researcher and the colleague were made and discrepancies were resolved by discussion. The researcher read the transcripts repeatedly in order to become familiar with the content, making notes and annotating the transcripts as necessary. Statements were selected from each of the transcripts to identify areas that were important to the participants. A set of codes was used to identify emerging areas of significance. The two main themes identified from the codes were: views of the direction of the PEC and concerns about the PEC. Each of these themes will 


\section{Maxine Offredy}

Table 2 Personal attributes

List of personal attributes

Degree of relevance in my role as a PEC member
Possession

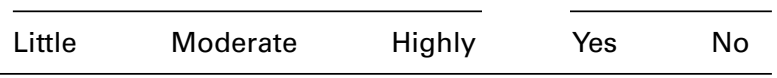

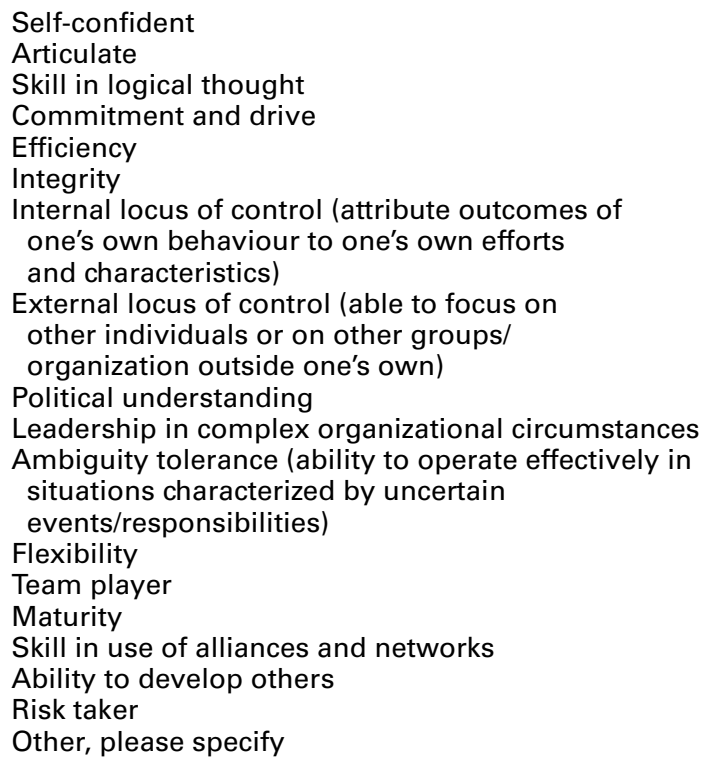

Do you have any experience of working at a national or local corporate level? Yes/No (delete as appropriate)

Table 3 Training needs of PEC members: intellectual

\begin{tabular}{lllll}
\hline Skills and knowledge & Possess & $\begin{array}{l}\text { Requires } \\
\text { further } \\
\text { training }\end{array}$ & $\begin{array}{l}\text { Requires } \\
\text { initial } \\
\text { training }\end{array}$ & $\begin{array}{l}\text { Not relevant } \\
\text { to PEC role }\end{array}$ \\
\hline Strategic understanding & 6 & 7 & 2 & \\
Analytical ability & 5 & 8 & 2 & 1 \\
Cultural flexibility & 2 & 11 & 5 & \\
Integrator & 3 & 5 & 7 & \\
Innovativeness & 3 & 7 & & \\
Work and develop plans and & 1 & & & \\
strategies with other agencies & & &
\end{tabular}

$n=15$

Adapted from Primary care trusts: establishment, the preparatory period and their functions (Department of Health, undated)

now be explained under the subheading of study findings, followed by a discussion.

\section{Study findings}

Although the analysis of the data was in two stages (use of SPSS for the questionnaires, and identification of themes from the interviews) the results are closely interlinked as the views of the PEC participants influence their perspectives about their perceived training needs, as identified in the questionnaires. Thus, there are overlaps in some areas.

The questionnaires and interviews highlighted two areas of concern. The first concern centred upon the question of the role of the PEC. Whilst the 
Table 4 Individual training needs

\begin{tabular}{lll}
\hline Name & Perceived training needs & Training strategy \\
\hline GP & $\begin{array}{l}\text { Health needs assessment, NHS finance, work and develop } \\
\text { plans and strategies with other agencies, risk management } \\
\text { Evaluation of organizational performance and } \\
\text { Non-GP }\end{array}$ & Internal, off-the-job course \\
& service delivery, time management, goal direction & Internal, off-the-job course \\
\hline
\end{tabular}

Table 5 Order of importance for PEC training needs

\begin{tabular}{ll}
\hline Intellectual & $\begin{array}{l}\text { Priority setting, strategic, } \\
\text { cultural, and integrator } \\
\text { Developing new services, data } \\
\text { Sevice issues }\end{array}$ \\
Finance commissioning & \begin{tabular}{l} 
Financial planning \\
\hline
\end{tabular} \\
\hline
\end{tabular}

guidance (NHS Executive, 1999; Department of Health, 2001) emphasized the need to have practising clinicians as the driving force to implement the core functions of the PCTs, taking into account local needs, participants argue that this is 'too vague' (participants 1, 3, 6, 9 and 11) and that 'the PEC has not clearly outlined its role' (participants 1,3, $5,7,12$ and 15). The second area of concern arose with the title 'professional executive committee'. Some PEC participants have said that the 'officers' (i.e., the management team) 'should execute' (participants 2, 3 and 7) and that the 'professionals' (i.e., members of the PEC) 'should advise and inform' (participants 2, 3 and 7). This means that there is tension between what is perceived by the PCT as the role, responsibilities and competencies of the PEC on the one hand, and the perspectives of PEC members, on the other, and this divided view gave rise to a feeling that the PEC is lacking in focus, as the following excerpts suggests:

The PEC feels a bit woolly to me because we haven't clarified what we are supposed to do, so that everyone has a common buy-in to the agenda.

(participant 5)

I'm not sure what outcomes we are looking for. The role is new and it's early days yet. We're still getting to know what the expectations of us are. There is some confusion about what we can do because we are only appointed for a few days a month.

(participant 11)
Some PEC participants (participants 1, 8 and 13) felt that other members of the PCT should undertake some of the competencies identified in Table 1. From the analysis of their questionnaires, the above participants felt ill-equipped to perform roles which required strategic functioning since they had no training at functioning at a strategic level, and some participants had 'little experience of board-level operations' (participants 2 and 5). Their area of comfort was 'operationally focused' (participants 2 and 9). However, one PEC participant felt frustrated with the way in which the PEC has been conceived by central government and stated that:

The PEC is a puppet organization of the government. The meetings are taken up with government targets and the local agenda is pushed aside. The targets for the PCT are political ones and not ones of quality that relate to patient care. At this stage, I really don't feel that I need any training, as I am afraid my time will be wasted attending any training sessions; I fear I will not be using those newly acquired skills.

(participant 7)

\section{Participants' views of the direction of the PEC}

Most PEC and stakeholder participants agreed on the issue of the clinical leadership role of the PEC and that it is placed to do more analytical and creative thinking about problems brought to it, as exemplified by the excerpts below:

Projects should come to the PEC with all available options, including risk analysis and clinical governance issues. The PEC would look carefully at the strategies of the options and set up work streams to look at each option. Each work stream would report back to PEC with complete pieces of work on 
which to base strong decisions that can be recommended to the board.

(participant 4)

The PEC could be in a very strong position to really bring about change because we have got some good clinicians on the committee, but it's early days yet.

(participant 13)

PEC members should have a sound understanding of the population, what its needs are now and in the future; look at that in terms of age, ethnic mix, social mix and plan services accordingly. They should be getting involved in change programmes and take responsibility for being the driving force for change. They may need several attempts at change as we are a complex organization and they may not get there in a straight line, but they need to keep checking the reference points to make sure that they will get to the point they want to get to.

(participant 26)

The PEC members need to know what outcomes they want and the financial effects or health impacts these will have when making suggestions.

(participant 20)

Others provide a different view of the PEC:

I see the PEC as translating government's expectations of a PCT to one of policy and implementation on the ground.

(participant 7)

To say the PEC is the 'engine room' is a misleading metaphor. Empowering the PEC by giving it freedom, but without direction, and without tools, e.g., administration/secretarial support, won't achieve much. Better metaphor is the PEC is the navigator, the board is the captain, and the engine room is the management team. The navigator will ensure that the ship sails in the right direction, so they have to engage with the engine room. A possible adverse consequence of this is we may end up with managerial solutions, which may not be sensitive to the needs of local practices or the needs of the local population.

(participant 15)
The PEC should be able to wear clinical, organizational and training hats. If you just have a clinical view then that's just putting nurses and doctors in their classic little boxes; they need to be able to cope with financial matters. They need to be creative and proactive.

(participant 18)

Several PEC participants welcomed the establishment of the PEC as it afforded the opportunity for:

clinicians and management to come together on one board so that clinicians have an input in the running of the organization.

(participant 8)

building on PCG's philosophy of working across professional boundaries.

(participant 3)

more transparent process and decision making that will hopefully reflect the local economy's needs.

(participant 12)

making a difference to patient/client care and to influence decisions at both primary and secondary care.

(participant 14)

\section{Concerns about the PEC}

The interviews revealed a consistent picture of participants' perception of the process of decisionmaking in the PCT. In essence, the majority of participants felt that they were the receiver of information rather than the driving force for making decisions, as highlighted below:

You get the impression that you are just rubber-stamping others' decisions.

(participant 5)

PEC meetings are used by the management team in order to justify management decisions to the PEC and to get a limited amount of clinical input as opposed to being a truly joint meeting.

(participant 9)

Another questioned where decisions were made:

Have we made a decision that's going to lead to action or does the decision for action gets made in a different place?

(participant 2) 
Other members felt that 'the PEC agenda was too centrally driven, leaving little room for local agenda' (participant 6); this gave rise to the view that they were 'being manipulated by the system' (participants 6 and 8).

Concern was also expressed about the length of the meetings, an average of four hours, which gave rise to "difficulty in concentrating for that length of time' (participants 3 and 14). Associated with the length of the meeting was the view that there were 'lengthy ineffectual discussions' (participant 4) since there was 'insufficient information on which to base a decision' (participant 2) and a 'lack of clarity about who sets the agenda' (participant 10).

Some participants felt that the meetings were 'dominated by doctors' (participants 3, 5,11 and 12) and were 'too primary care focussed' (participant 1 ); one participant 'felt uneasy about speaking on issues about which I know very little' (participant 3), resulting in the perspective that some members 'have not contributed to the discussions' (participants 3, 5 and 11). Further, it was perceived that there was 'nothing to do in between meetings' (participants 3, 5, 11 and 12). Two of these participants also realized that their lack of contribution during the meetings was reflected in the minutes of the meetings as they said that 'some names appeared against most discussion points' (participants 5 and 12), giving rise to the view that 'some people will talk on anything and everything' (participant 11). However, this should be balanced against the view of another participant who said that:

It is noticeable that some members of the group do not contribute to the discussion even when asked a direct question, or when everyone is asked if they have a comment to make.

(participant 12)

The introduction of PCTs brought new ways of working, but for some PEC participants it also meant that they started the new organization with a deficit and an emphasis on achieving financial balance at the end of the first year. This left some PEC participants feeling that:

It is difficult to take risks when we are always told that we can't afford certain services. (participant 1)

We are in danger of becoming a 'can't do' organization.

(participant 4)
The PEC agenda is cost-driven. The bottom line is always cost and people are turned off by that, but it is recognized that cost will always be a factor because if you identify problems that need drug treatment, that will increase drug spending.

(participant 22)

On the other hand, one participant thought that:

The PEC doesn't seem to understand the impact of a unified budget or what working within a finite budget entails.

(participant 7)

Other concerns of the PEC included views about involvement of its wider constituents and public participation in decision-making, as indicated below:

GPs' views are not heard because nobody asks for suggestions or ideas from non-PEC GPs. Unless you are in a practice with one of the PEC members or in the group that sits together to think about things, then you're outside.

(participant 20)

I recognise that the PEC has a difficult job because there is difficulty in getting the information together to involve the constituents because the government keeps moving the goal post.

(participant 16)

I really want to see public involvement. We can attend public meetings and have our say, but I don't know how that is going to be translated into policies. As far as I know there is no collective voice for the public to get involved in the decision-making process.

(participant 15)

\section{Discussion}

It is clear from the data the role of the PEC had not been clearly identified. This is not surprising, as the government had vaguely defined their role and detailed clarification was left to individual PCTs. Perhaps part of the problem lies with the PCT board in that a clear remit about the PEC's role should have been discussed with them. This is important for two reasons. First, clarity of the PEC's role 
would pave the way for them to provide leadership to local clinicians, and other health and social care staff to engage them in the PCT's agenda for modernization and change. Secondly, role clarification is essential as the PEC plays a part in the development of managed clinical networks and in securing co-ordinated and seamless care for the PCT's patient population. In addition, lack of role clarification obscures both real and perceived training needs and to a large extent reflects some of the views expressed in the previous section.

However, the matrices developed for the group and the individual participants represent a starting point in identifying training issues for operating in complex organizational circumstances. For the PEC as a whole their training needs include priority setting, strategic understanding, developing new services and financial acumen. Similar areas have been identified in earlier work (Department of Health, 1994; Dawson et al., 1995). Some participants identified attributes that they do not possess and would welcome input on these. They are: the ability to develop others, being a risk taker and being a motivator. One way of identifying suitable members for the PEC is to have role clarification from the PCT, upon which to base interviews. The skills and knowledge listed in Table 1 could be a starting point.

In its reforms of the NHS, the government continues to stress the importance of interdisciplinary team working, where all those who contribute to patient care work together to provide a seamless service to the patient (Department of Health, 1997). This in turn requires streamlining of the services and the development of new approaches that makes the best use of people's skills. This goal is unlikely to be achieved if the PEC does not have a clear remit of the work required of it. This level of clarity would enable identification of the types of skills and interest within the group so that particular task could be allocated to small groups who in turn would report back to the larger group. This process has twin advantages of overcoming some of the reticence some members feel about engaging in discussions in a large group, and the view that there is little to be done between meetings. The result of this would be that meaningful discussions can take place during PEC meetings and in-depth answers can be obtained about issues raised so that proposals can be placed before the board for their consideration. This would be a step towards role clarification and ultimately training needs.

\section{Conclusions}

Overall, all participants expressed some positive views about the creation of the PEC, but this was tempered with real and practical concerns of its functioning. Some of the difficulties facing the PEC were not of its own making but were due to the rapid nature of organizational change in the NHS. The PCT's organizational structure was still developing (at the time of data collection), so within this context it was very difficult for the PEC to start delivering its objectives. The roles and functions of the PEC were vague and this was a contributory reason for many of the issues raised. However, the PEC had not found a way of working to realize the creative potential of its members. The study has shown that identifying the training needs of PEC members is not a simple task and the competencies outlined in the guidance (Department of Health, undated) can miss important aspects of the organization. Crucially, the PEC must clarify its role in order to facilitate greater clinical ownership and begin to contribute to the modernization agenda. Future research could address the extent to which the PEC role has been clarified and whether this has been helpful in contributing to redesign of services.

\section{Acknowledgements}

I am grateful to the National Primary and Care Trust Development Programme (NatPaCT) and West London Research Network (WeLReN) who provided financial support for this project.

\section{References}

Benton, D. 1997: New horizons. Nursing Standard 11, 24.

Burgoyne, J. and Lorbiecki, A. 1993: Clinicians in to management: the experience in context. Health Services Management Research 6, 248-59.

Craig, G. 2002: Primary care trust and local health group executive committee pharmacists: the story so far. The Pharmaceutical Journal 268, 59-60.

Dawson, S., Winstanley, D., Mole, V. and Sherval, J. 1995: Managing in the NHS: a study of senior executives. London: Her Majesty's Stationery Office.

Department of Health. 1994: Building a stronger team: the nursing contribution to purchasing. Leeds: NHS Executive. 
Department of Health. 2000: The NHS plan: a plan for investment, a plan for reform. London: Her Majesty's Stationery Office.

Department of Health. 2001: Shifting the balance of power within the NHS: securing delivery. London: Department of Health.

Department of Health. 2002a: Shifting the balance of power: the next steps. London: Department of Health.

Department of Health. 2002b: National Service Act 1977. Primary care trust (procedure and administration arrangements) directions 2002. London: Department of Health.

Department of Health (undated): Primary care trusts: establishment, the preparatory period and their functions. London: Department of Health.

Duffy, M. 1985: A research appraisal checklist for evaluating nursing research reports. Nursing and Health Care 6, 539-45.

Fitzgerald, L. 1994: Moving clinicians into management: a professional challenge or threat? Journal of Management in Medicine 86, 32-44.

Fitzgerald, L. and Sturt, J. 1992: Clinicians into management: on the change agenda or not? Health Services Management Research 5, 137-46.

Greenhalgh, T. 1997: How to read a paper. London: BMJ Publishing Group.

Harvey, S. 1994: Put the gem in stratagem. Nursing Management 1, 24-25.

Kaufman, G. 2002: Investigating the nursing contribution to commissioning in primary health-care. Journal of Nursing Management 10, 83-94.
King's Fund College. 1993: The professional nursing contribution to purchasing. London: King's Fund.

Maddock, H. 2001: Pharmacy must be represented when the balance of power is shifted. The Pharmaceutical Journal 267, 223-34.

NHS Executive. 1999: Primary care trusts: establishing better services. Leeds: NHS Executive.

Office for National Statistics. 2001: Census 2001: report for England and Wales. London: Office for National Statistics.

South East Thames Regional Health Authority (SETRHA). 1992: Nurses and purchasing - starting the debate in South East Thames. Sussex: SETRHA.

Taylor, P.J. and O'Driscoll, M.P. 1998: A new integrated framework for training needs analysis. Human Resource Management Journal 8, 29-50.

Thorne, M.L. 1997: Being a clinical director: first among equals or just a go-between? Health Services Management Research 10,205-15.

University of Birmingham. 2000: Prescribing advisers: a new breed of professionals in the primary care team. The Pharmaceutical Journal 264, 192.

Wilcocks, S. and Conway, A. 2002: Managing the 'seamless service': primary care groups in the new NHS. Health Services Management Research 15, 106-15. 